\title{
Scenario-Based Private/Instrument Syllabus versus Traditional Maneuver-Based Syllabi: A Preliminary Descriptive Analysis
}

\author{
Paul A. Craig, John E. Bertrand, Wayne Dornan, Steve Gossett, and Kimberly K. Thorsby \\ Middle Tennessee State University
}

\begin{abstract}
The Aerospace Department at Middle Tennessee State University and the NASA Langley Research Center entered into a cooperative agreement in 2003. The project is named the SATS Aerospace Flight Education Research (SAFER) and is part of NASA's Small Aircraft Transportation System (SATS) initiative. The SATS project envisions a future flight environment that employs light aircraft to transport people and cargo from point to point using small, under utilized airports, instead of the major gridlocked airports. The aircraft used in the SATS vision would take advantage of a range of emerging technologies including glass cockpits, new structures, and new engines. But with the understanding that the best aircraft and the best systems are still only as good as its operator, MTSU Aerospace set out to explore how pilot training might be different in the SATS environment. The SAFER project therefore takes beginner pilots and completes their initial Visual Flight (VFR) and Instrument Flight (IFR) flight training in technically advanced aircraft to determine how best to educate the next generation of pilots in the next generation of aircraft. The availability of information from an automated flight deck can be easily adapted to scenario-based training, so the SAFER researchers decided to incorporate scenario, rather than strictly maneuver-based training as the core of the training syllabus. This approach instantly begs the question: If you train using a scenario-based method, will the students also develop the "stick and rudder" skills that are also so important for pilots to master? The early results from the SAFER project indicate that piloting skills (stick and rudder) are being mastered despite the scenario-based method, and that decision making skills are being increased.
\end{abstract}

\section{INTRODUCTION}

Light airplanes with advanced avionics and flight management systems are on the market today, but inquiry into how best to teach using this equipment either does not exist or is very limited. These advanced systems have reached the market before thorough testing of "best practices" has been conducted and already several "automation induced" accidents have occurred (General Aviation TAA Safety Study, 2003). The SAFER project is one attempt to do the testing and make discoveries to prevent additional accidents. Specifically, the SAFER project has two primary objectives: 1) to learn what old topics of instruction are becoming obsolete with the introduction of advanced systems, and 2) to learn what new topics/problems will arise as we begin learning in "glass." In 2004, flight training began within the SATS Aerospace Flight Education Research (SAFER) project. Students were taught in Technically Advanced Aircraft (TAA), using a FAA approved, scenario based syllabus that leads to a single Private Pilot and Instrument Rating practical test.

\section{THE RESEARCH QUESTIONS}

The researchers of the SAFER project are in the preliminary stages of the data collection. The project is on going and the final report of findings will come at the conclusion of the project. The researchers are gathering data to help answer some of the basic research questions: If you teach people to fly from the very beginning using scenario-based training rather than maneuver-based training, will "stickand-rudder" skills suffer? Will scenario-based training produce pilot who are better prepared to operate safely in the real world flight environment?

\section{METHOD}

The researchers utilized a qualitative approach as outlined by Bogdan and Biklin (1998), which includes an intense data collection 
process. Observations were taken from many angles, including primary observations, coding and analysis, record keeping, and journal writing on the part of students, instructors, coordinators, and researchers. The data presented in this paper represents just one form of data acquisition used by the SAFER researchers and should be considered a sub-set of the total data being collected within the project. For this analysis, the subjects had recently completed the scenario-based training in Garmin G-1000 equipped Diamond DA-40 aircraft and were given a post syllabus completion, evaluation flight. The students had received a private certificate with instrument rating having amassed less than 104 hours total time and without the normal divisions between the two certificates/ratings.

All the students of the SAFER project are college students majoring in Aerospace at Middle Tennessee State University. To become eligible for the SAFER project students had to meet two criteria. First, they must have already been accepted into the program's flight laboratory, which requires a 2.5 cumulative college GPA, or a 2.8 high school GPA for incoming freshman students. Second, the students must have had less than five flight hours of experience with a flight instructor. These students were also enrolled in a separate section of AERO 2230, which is the Private Pilot Fundamentals course. In this special SAFER section of the course, a new approach was utilized. Instead of the traditional private pilot curriculum, the course taught decisionmaking skills. The course content included the analysis of NTSB accident reports and hazardous pilot attitudes. Students prepared themselves for the regular FAA Private Pilot and Instrument Rating knowledge tests with their individual flight instructors, in weekly study sessions, and on their own. Fourteen students formed the first cohort of SAFER students. The training began in September 2004 as the fall semester started. At the time of this writing, nine of the fourteen students have completed the program, having passed the single practical tests to become Private and Instrument pilots. The second cohort began in January 2005 as the spring semester started.

\section{THE EVALUATIVE FLIGHT}

After receiving the private license with instrument rating, the students were asked to participate in a flight designed to assess a variety of skills. The performance of the students would then be compared at a later time to students who had received the instrument rating in the traditional fashion. The evaluative flights were conducted under Visual Meteorological Conditions (VMC), with the researcher acting as Safety Pilot.

Students were given 10 minutes preparation time. The scenario was as follows:

1. The initial instruction was to depart Airport A and proceed to Airport B (about $50 \mathrm{~nm}$ ). Soon after departure, the researcher deactivated both screens of the G-1000. The student was therefore forced to precede using dead reckoning and pilotage across an area containing few landmarks and roads. Upon arrival at Airport B, the student was instructed to execute a touch and go and climb out, departing to Airport C.

2. As soon as the student reached altitude, the researcher failed the engine, requiring the student to execute a simulated emergency landing.

3. As the student climbed out from the simulated landing, he/she was instructed to don a vision-limiting device and go on instruments, at which time the researcher reactivated the screens. The student was instructed to proceed to Airport $\mathrm{C}$ and shoot the SDF approach, with the researcher acting as ATC.

4. On the way to Airport C, the researcher required to the student to execute steep turns to 45 degrees under the hood. This was followed by recovery from very unusual attitudes, which went nearly to the edge of what is defined as aerobatic flight. These were done with little setup and some urgency from the researcher, as if to avoid an obstacle or allow the researcher to see something on the ground.

5. The student was, of course, required by this scenario to set the avionics up for the new destination. As soon as the 
student depicted the approach final course on the screen, the researcher, as ATC, required vectors that ensured a very dis-advantageous intercept course, that is, one which would require a very steep turn to intercept from an oblique angle. The student was then instructed to conduct a touch and go after raising the hood at one mile distance from the touch-down point.

6. Following departure from Airport $\mathrm{C}$, the student was instructed to fly to the missed approach hold and fly the published hold, while under the hood. This involved a 180 degree turn from the departure course and setting up the avionics while climbing out. After the second turn around the hold, the student was instructed to depart to Airport D.

7. Soon after turning to Airport D, the student was contacted by the researcher as ATC and told to report ready to copy an amendment to clearance. The amendment instructed the student, for reasons of national security, to intercept the nearest segment of a nearby Standard Terminal Arrival Route (STAR) to a Class $\mathrm{C}$ airport. The instructions were to first proceed to the nearest STAR transition and then follow the STAR procedure to the Class C airport.

8. The student, upon intercepting the STAR, or not, was allowed then to return to the origin of the flight, Airport A, and execute the GPS approach. The student was allowed the remove the hood at one mile from the touch down point and land.

This flight addresses a number of issues, which a pilot might encounter in real life (Parasuranman, 1997). These include changing destinations and clearances, failed equipment, emergencies, stick and rudder skills, and maintaining safe attitudes while engaged in a number of potentially distracting activities. This preliminary report will address only stick and rudder skills.

\section{THE TRAINING SYLLABUS}

Five airplanes were taken from the MTSU flight training fleet for exclusive use in the SAFER project. Each was equipped with the Garmin G-1000 system and autopilot. The features of the Garmin G-1000 system make it possible to blend the world of visual flight and the world of instrument flight - but that is not the traditional way that students are taught today. Students are taught visual flying first and pass a series of tests to obtain the Private Pilot Certificate. The Private Pilot then takes on additional training and testing to become Instrument Rated and this allows the pilot to fly in and through the clouds. The Primary Flight Display of the G-1000 provides a representation of the horizon that is far advanced from basic attitude gyro indications.

Part of the cooperative agreement with NASA called for the SAFER project to work in conjunction with the FAA Industry Training Standards (FITS) initiative. The FITS group had previously developed a generic flight training syllabus that combined the training for both Private Pilot and the Instrument Rating into one. The SAFER team took the generic FITS combination syllabus and rewrote it for specific use at MTSU. In time, the syllabus was approved by the FAA under Part 141 and added to MTSU's existing Air Agency Certificate. The MTSU version of the FITS syllabus (2004) became the first combination Private and Instrument Course for Technically Advanced Aircraft ever approved by the FAA.

The syllabus is unique in two other important ways. First, the entire combination Private and Instrument course is scenario based. Traditionally, pilots are trained using a series of maneuvers that the student masters with drill and practice. The SAFER syllabus still teaches basic skills, sometimes referred to as "stick and rudder" skills, but instead of drill and practice, the maneuver is incorporated into an overall scenario lesson. The very first lesson of the SAFER syllabus is a flight to another airport - a mission, rather than a set of maneuvers. The second unique feature of the SAFER syllabus is that it has no minimum flight time requirements. Traditionally trained students must meet several minimum flight time requirements to move from 
one step to another and to receive FAA pilot certification. It would be possible for a pilot to have achieved an acceptable performance level in a particular area of training, but still be required to take additional training just to reach the minimum flight time number. Students in the SAFER project are judged by performance only, not flight time. When students complete each lesson of the SAFER syllabus they are recommended for testing regardless of how many or how few flight hours they have accrued. At the time of this writing, nine of the original (Fall 2004) fourteen students of the SAFER first cohort have completed the SAFER syllabus and have passed the combined Private Pilot and Instrument Rating practical test. The student who had the lowest time at completion had 74.5 flight hours and the highest had 104.1. The average time to complete was 88.74 flight hours.

\section{THE FAA EXEMPTION}

A major problem for the SAFER students is that they are training in a time of transition. The syllabus that they use and the airplane that they use are all new, but the FAA testing is old. Today, the Code of Federal Regulations 14, Part 61.65 (a) (1) (2005) requires that an applicant for the Instrument Rating, already be the holder of the Private Pilot Certificate. But the SAFER syllabus bypasses the Private Pilot test when students would otherwise be eligible to take it. Instead, the SAFER students remain as student pilots until the day that they take the combination test and become Private Pilots and Instrument Pilots all at once. So the SAFER syllabus, is in fact, in violation of the Federal Aviation Regulations. To remedy this problem, the SAFER researchers petitioned the FAA for relief from 61.65(a) (1) and on December 10, 2004, the FAA granted an exception to this rule for the SAFER project. FAA exemption number 8456 (2004) allows the SAFER students to take a single practical test to gain both Private Pilot and Instrument Pilot privileges. The exemption came with a new Practical Test Standard (PTS) that is to be used by a pilot examiner when administering the combination test. The exemption has only been granted to MTSU and the SAFER project and extends until December $1,2006$.
The exemption has not eliminated all "old versus new" roadblocks to the training. The SAFER students still are required to take two knowledge tests that are administered via computer. The two tests contain questions that are not applicable to technically advanced aircraft. The new PTS that came along with the exemption is better than two separate tests, but still requires many drill-and-practice type maneuvers that do not match well with the SAFER scenario based syllabus. This forces the SAFER students to step out of the role of the scenario and occasionally revert back to pure maneuver practice simply to meet the requirements of the test. Using the old form of testing with the new form of training has become a very real impediment to the students that lengthens the time of training and pushes instructors to "teach to the test" rather than "teach for the real world" as the SAFER project intends to do.

\section{RESULTS}

The stick and rudder skills addressed by the evaluative flight may be described as follows:

a. The failed G-1000 trip to Airport B causes the pilot to navigate, approach, and land without instrumentation of any kind.

b. The simulated emergency causes the pilot to maneuver to land without instrumentation of any kind.

c. The ATC instructions to intercept the SDF invite the pilot the engage in a very steep turn under IMC to get the inbound course.

d. The climb out from Airport $\mathrm{C}$ invites the pilot to be distracted while rapidly setting up the avionics under IMC and executing a 180 degree turn.

e. The unusual attitudes and steep turns are a direct measure of the pilot's ability to respond to sudden needs to maneuver under IMC.

It may be said that the whole scenario was set up to invite pilots with fewer than 100 hours total time to engage in a series of activities wherein the possibility of an upset, tight spiral, or stall could be anticipated.

The outcomes indicate that these students, despite having been trained with scenarios rather than maneuvers as the emphasis, still have a 
high degree of stick and rudder skills. At no time did any pilot in fact become upset, get near stall conditions, or enter even an incipient tight spiral. Examples follow:

a. When the researcher suddenly yelled, "Man, look at that, it's a Pitts just below us. I got to look at that. My airplane" and entered a steep turn to 45 degrees bank with 15 degrees down nose, the students returned the aircraft to straight and level without comment or incident when the researcher said, "OK, your airplane" while still in the unusual attitude.

b. No student could be induced to accept the steep intercept angle on the SDF. All either maneuvered to avoid the angle or requested an amendment from ATC.

c. Students flew and landed with avionics failed and blank screens using pilotage and dead reckoning without any discernable discomfort.

d. Students maneuvered for a forced landing with blank screens without discernable discomfort.

e. No student had any difficulty in simultaneously setting up the avionics, turning, climbing, finding the published hold and flying it given no warning of the need until about 100 feet off the ground going in the opposite direction.

\section{CONCLUSIONS}

In order to successfully complete this evaluative flight, students with fewer than 100 hours total time were required to fly entirely from outside reference and land, maneuver for a forced landing from outside reference only, recover from steep turns and very unusual attitudes under simulated instrument conditions, and fly under distracting conditions under simulated instrument conditions. The purpose was to mimic as closely as possible the stick and rudder skills that a pilot might encounter in the real world. No pilot failed to perform safely, and no pilot succumbed to distractions.

It appears from these data that the teaching of formal stick and rudder skills such as turnsaround-a-point or rectangular course may be of little utility if they are subsumed into the day-to- day reality of scenario training. The pilots in the SAFER Project do not perform worse than their contemporaries who have received formal, repetitive maneuver training; rather, they perform as well or better. Further, their ability to cope with changes, amendments, and demands for performance seems more than up to the various tasks.

The formality of formal maneuvers appears to be some of the problem. The Practical Test Standard (PTS) requires a down wind entry for turns-around-a-point, for instance, and sets standards for altitude, roll out, and so on. However, when SAFER students are presented with turns around the end of an emergency landing field, they perform very well.

The evidence at this point tends to support the claim that all the time and money spent on formal maneuver training in traditional syllabi appears to be immaterial when applied to scenario training in TAA. SAFER students perform admirably in the real world to the extent that the evaluative flights were able to mimic it and appear, in addition, to cope on levels more associated with two or three hundred hours total time, rather than 85 to 90 -hour pilots. The SAFER researchers believe that the concerns expressed in reference to stick and rudder skills are unfounded, but work continues to evaluate a larger sample size.

\section{FINAL THOUGHTS AND RECOMMENDATIONS}

The SAFER researchers should not be characterized as "anti-maneuver." We fully advocate the strong teaching of skills that will lead to excellent "stick-and-rudder" control of the airplane in all flight circumstances. But our research has led us to believe that these essential pilot skills can be acquired within scenarios that mean something to the student rather than repeated drill and practice maneuvers that have no real-world context. It appears that the art of landing an airplane, for example, still requires several practice repetitions beyond the number received within the scenarios alone. Consequently, the movement from maneuverbased to "mission-based" training is a spectrum rather than a single step. 
The biggest impediment to implementation of the scenario-based training approach is the current method in which pilots are tested. Technology improvements have been made rapidly while the pilot testing procedures have remained relatively unchanged (The most recent Practical Test Standards for the Instrument Rating does require some scenario-based training, but no further guidance is given to examiners, applicants, and instructors). The data collected to this point is preliminary, yet the researchers are compelled to call for sweeping reform of pilot testing in light of what has been discovered. We understand that maneuvers are easier to grade, but they do not prepare the pilot for real-world challenges found in today's flight environment. A flight testing procedure that grades pilot skills while immersed in real-world scenarios would be a better evaluation of a pilot's readiness for operations within the national airspace system. Scenario-based testing would require a shift in approach and evaluation techniques. Examiners would need to grade pilots based with the understanding that in any given situation there may be an array of "correct" decisions, and each could insure a safe outcome. The Practical Test should incorporate all skills necessary for a pilot to safely complete a flight from one airport to another, but eliminate maneuvers that would not otherwise be normally required during that flight.

To make this shift in testing methodology a reality, additional data will be needed. The SAFER research is ongoing and additional

Research should be undertaken. The FAA will soon be forced to make changes or find themselves in danger of being completely behind the technology and methods of the times. It is our hope that this research, and others, will help make the transition possible and timely.

\section{CONTINUING SAFER RESEARCH}

In the fall of 2004, the first SAFER cohort began flying and using the combination Private/Instrument syllabus which is both FITS accepted and FAA Part 141 approved. The first cohort completed every lesson in an airplane. In the spring of 2005 the second cohort of SAFER students began, also using the combination syllabus, but those students had access to a
DA40 / G-1000 flight training device to complete all ATD lessons from the syllabus. In the fall of 2005, the third cohort of SAFER students will begin. The third cohort will fly in the TAAs but will use a traditional instrument syllabus, rather than the combination syllabus. Data and analysis from the second and third cohorts will be available when completed 


\section{REFERENCES}

Bogdan, R.C. \& Biklin, S.K. (1998). Qualitative research in education: An introduction to theory and methods. Boston, MA: Allyn \& Bacon.

Code of Federal Regulations 14. (2005). Federal Aviation Administration Part 61.65(a) (1). Washington, DC: U.S. Government Printing Office.

Federal Aviation Administration. (2004). Regulatory Docket Number FAA-2004-19151. (Exemption Number 8456). Washington, DC: U.S. Government Printing Office.

General Aviation TAA Safety Study. (2003). Washington, DC: Federal Aviation Administration.

MTSU Aerospace (2004). Scenario Based Private/Instrument Pilot Certification Course Syllabus for Technically Advanced Piston Aircraft. (2004). Murfreesboro, TN: MTSU Aerospace.

Parasuranman, R. (1997) Humans and Automation: Use, Misuse, Abuse. Human Factors 39(2), p. 230253 